\title{
Access to Credits and Erosive or Non-erosive Coping Strategies: An Empirical Analysis in Bangladesh
}

\author{
Meherun AHMED", Iftekhar Uddin Ahmed CHOWDHURY*, Sabiha Subah MOHONA ${ }^{* * *}$
}

\begin{abstract}
This paper uses household-level data from a nationally representative survey conducted in 2009 and 2010 in Bangladesh to determine the relationship between coping mechanisms and having access to credits. The analysis finds that more than half of the sample claimed to have faced shocks over the years. The paper also discusses the coping strategies households undertake after experiencing economic shocks. As Bangladesh is prone to natural disasters, some climatic shocks are annual in certain parts of the country. A lot of factors influence the coping strategies taken by the households. Poorer households are more likely to use coping mechanisms that may have negative implications in the long run as they include the depletion of capitals, assets, savings etc. An econometric model is used to address what might help them to cope better and whether having access to any kind of credit can help them cope, i.e., help them to take non-erosive measures when they face shocks. Policy implications include the importance of developing government programs, safety net programs and developing the networks of microfinance organizations.
\end{abstract}

Keywords: Access to Credits, Coping Strategies, Erosive Coping, Income Shock, Microfinance, Natural Disaster.

JEL Codes Classification: 131, 012, Q54

UDC: 336.77(549.3)

DOI: https://doi.org/10.17015/ejbe.2017.019.01

* Associate Professor, Department of Economics, Asian University for Women, Chittagong, Bangladesh

Email: meherun.ahmed@auw.edu.bd.

** Lecturer (Corresponding author), Asian University for Women, Chittagong, Bangladesh.

Email: iftekhar.chowdhury@auw.edu.bd

${ }^{* * *}$ Research Analyst, The World Bank, Dhaka, Bangladesh. Email: smohona@worldbank.org

Copyright (C), 2017 International Ataturk Alatoo University. 


\section{Introduction}

Bangladesh is prone to natural disasters. Even besides natural disasters, the residents face a number of economic shocks because Bangladesh is a developing nation. Every year it faces natural calamities which affect the rural people distinguishably more than the urban. While all households are affected negatively by any economic shock, poorer households are more likely to face difficulties and challenges to recover the damages. This has been a topic of interest and there are a good number of studies on how households cope with risks using various strategies. It is important to analyze coping strategies since some shocks may lead to a long-term negative effect which might result in chronic poverty.

When a vulnerable household faces an economic shock and the household has to resort to erosive coping strategies to mitigate the loss, there is a strong likelihood that the household may not be able to recoup the productive assets. Thereby, they suffer a loss in productivity leading to a loss in future income generating capacity in the given household.

The household may fall into vicious poverty trap if the loss in productive assets is significant. There are also other associated long run consequences of this loss.

The impoverished household may not be able to invest at all or invest in lower quality health and education of the future generations, leading an intergenerational cycle of poverty entrapment. This process has adverse implications for the inequality, poverty and overall growth and development of the country.

Shocks and risks can be of different types, for example, idiosyncratic risks which affect one specific household or a small group of asset and systematic risks that affect an entire village or community and other aggregated outcomes. Coping strategies can also be defined into many categories. There are ex-ante and ex-post measures to cope up with economic shocks. Ex-ante measures are the preparations taken before any shock takes place and ex-post measures are the measures taken after the shock to mitigate the consequences. In most cases, shocks are unpredictable and people are unaware of upcoming natural disasters or shocks. Sometimes, life after the shock is harder than surviving the shock. For this paper, the focus is on the strategies taken after facing any shock which can be defined into two categories, erosive and non-erosive. Erosive measures include all the measures that have a long-term negative effect and non-erosive is the opposite. Poorer people are considered to be more vulnerable because they are more likely to adopt erosive coping strategies to recover any income shock. Whereas well-off households are considered to be less vulnerable for the fact that they usually do not have to take erosive coping strategies since they are aware of non-erosive coping measures such as various government and private insurances, having access to formal, informal or quasi-formal credits etc. 
As mentioned above, coping strategies do depend on several factors. Such as: the degree of damage caused by the shocks; types of shocks; ability to recover; awareness depending on the geographical location; knowledge and information about the opportunities etc. One of the many important factors is whether the household has access to any credit which plays quite an important role to determine the coping strategies of households. Households can take help from the government safety net programs, NGO programs or they can have government or private insurance to cope up. However, providing insurance to the rural people is difficult for the lack of awareness, lack of information and transaction costs. Microcredit institutions are playing a very good role to help poorer people nowadays in Bangladesh. People don't tend to sell their assets, use up their savings or, take help from relatives to recover the damage if they usually have access to credits and if there are no limited insurance markets.

A nationally representative dataset from Bangladesh has been used in this paper to analyze the coping strategies of households and whether they adopt erosive coping or non-erosive coping strategies and whether they have access to any credit system when they get affected by any income or economic shock. Taking erosive measures might cause capital depletion in the long run and individual households might face difficulties recovering the damage which can result in chronic poverty. The data also helps to analyze by six different divisions in Bangladesh. It's important to analyze it by divisions because type of shocks varies with location and the measures taken to reduce damage largely depend on the type of shocks.

\section{Literature Review}

There are several pieces of researches on the natural shocks of Bangladesh and coping strategies and a very few of them talk about the erosive coping measures which may cause long-term negative effects. The review of some important and extensive researches related to economic shocks and coping strategies is provided in this section for a broader idea which would help the research of this paper.

Opondo (2013) in his research called "Erosive coping after the 2011 Flood in Kenya" tried to address and define what falls in the erosive coping category which is also very important to know for this research. He looked into the impacts of flooding and the coping strategies that the affected people adopted. Later in his research, he found out that many of the coping variables that people use are erosive as they have long-term negative effects in the household sustainability. According to him the sale of property, and livestock, withdrawing children from school and involving them in child labor, reducing expenditure on household activities, migration, and temporary relocation etc. fall under the category of erosive coping strategy. These strategies generate problems in future in particular the depletion of capital, poor educational attainment for children, poor living conditions and lack of proper health care etc. (Opondo, 2013). This paper discusses how erosive measures can be decreased and whether there is any effective way to cope up risk other than taking 
erosive measures. The data of Bangladesh used for this study provides detailed information on households which helps us to see the relation among erosive coping mechanism and other variables. Variables like cope risk using savings, cope risk using advanced labor sale, cope risk using advanced crop sale, cope risk using asset sale, cope risk using relative support and cope risk using private support have been considered as erosive coping strategies.

Erosive coping in this paper is defined following the standard definition by World Health Organization (WHO). Their definition includes disposal of productive assets, shark loans, the sale of large livestock, land and tools, bonded labour arrangements, and child labour. The major distinction between their definition and the one implied in the paper is shark or usurer loans.

Our definition of erosive coping does not include shark loans separately. Most of the rural population, especially for agricultural households does not borrow from formal banks. The percentage of shark loans from usurers has greatly diminished over the years with the expansion and access to micro-credit. In our data about 50.7 percent of the sample who faced any shock adopted non-erosive coping mechanisms and 49.3 percent adopted erosive coping schemes.

Taking a loan or borrowing is no less erosive than drawing down savings or accepting help from relatives. That is why our principal independent variable, "any shock last year" is interacted with access to credit. This interaction term will capture the joint influence of the impact of borrowing from any source, formal, informal and microcredit of those who suffered any income shock, on the likelihood of adoption of erosive coping. We defined access to credit including formal loan, microfinance loans and most particularly informal credit some of which may be shark loans. Thus our principle independent variable captures the impact of role of credit in adoption of erosive coping for the people who faced any type of shock last year.

Brouwer et al. (2007) defined coping mechanism into two categories, ex-ante and ex-post coping mechanism. They investigated the adaptive coping mechanism of vulnerable households and the complex relationship between the environmental risk and poverty. As mentioned above ex-ante measures are taken as preparation before shock and ex-post measures are taken after being affected. The paper looked into the ex-ante household preparedness and also ex-post availabilities of coping mechanisms. They used their own analytical model to show that household with lower income and less access to productive natural assets face higher exposure to risks. The paper also demonstrated that the households exposed to more risk are usually the ones with the least prepared both in terms of ex-ante preparedness and ex-post availabilities.

There can be several ex-ante strategies depending on the geographical location, income of the households, education etc. Households of geographically more vulnerable areas are more aware and prepared for damage than the others but still 
those households tend to be more affected as they may face repeated shocks. It's interesting to see the variations in the findings of Yamauchi et al. (2009). They showed that in Ethiopia, public assistance plays a more important role than ex-ante actions in mitigating the impact of shocks and in contrast, Malawi households rely more on private ex-ante actions than on public assistance. And in Bangladesh both ex-ante and ex-post actions are important. On the other hand, Santos et al. (2011) concentrated more on ex-post strategies that households take after the shock. The research studied whether the various ex-post coping strategies are dependent on the nature of shocks and income of the households. Their economic analysis suggests that geographical location, socio-economic status, access to microfinance etc. affect the ability to cope. Their study also showed that the poor are more likely to use coping strategies that can have negative welfare implications in the long run. This paper does not only discuss the vulnerable ex-post strategies, their variation according to geographical location and economic status but also some effective ways to cope up that can maintain an inverse relationship with the strategies having long term negative impact.

Kuchler, Longborg and Nielsen (2012) researched on the variety of mechanism to cope with shocks in one of the poorest countries namely Mozambique. They polished off the research by dividing the dataset into two parts; one part has poorer households than other. Their study found out that both richer and poorer households cope up risk but poorer households have limited access to credit markets. And on the other hand, cash credit is only available to richer households. Though their dataset constrains them from concluding this fact with proper indicators they end up finding that the poorer households smooth out consumption through financial and labor market. The recent data set for this paper provides sufficient information to conclude how rural people are exposed to credit markets and the effects of having access to credits in the context of a developing country like Bangladesh.

According to Hodgson's (1995) research, improved housing is not the most appropriate aid in the immediate post-disaster phase in Bangladesh but the development of community structures are necessary for the long term. Park (2006) looked into the behaviors of households during an economic hardship depending on the membership status in a neighborhood network and relationship to their neighboring households. He found out that economic shocks are less likely to have lower effect on the behaviors of households pooling risks with others in an informal insurance network than on those who do not belong to any network. This paper uses a recent dataset of rural households in Bangladesh to uncover sort of similar findings in a more comprehensible and analytical way by establishing a relationship with some coping measures.

Varangis, Skees and Siegel (2002) focused on risks that are related to weather events that have severe impacts on rural income in developing countries, especially where farming is one of the major sources of income. They used Mexico as a case 
study to support their findings. According to their study, lack of availability of coping measures is caused due to inadequate credit availability and inadequate access to credits. Either the farmers have less access to credits or they exhibit highrisk aversion and do not tend to borrow. Diagne and Zellar (2001) studied the impact of access to credits on household welfare in Malawi, a landlocked country in southeastern Africa. Their findings showed that the marginal effects of household farming and non-farming incomes resulting from mere access to formal credits are positive. They did not look into the overall situation specifically as an ex-post coping mechanism. Pasha and Negese (2014) studied major socio-economic factors and loan related factors that determine loan repayment performance of borrowers in Ethiopian microfinance institutions, where microfinance is relatively new to Ethiopia and came to existence during 1994-95. Based on their analysis, they suggested that proper training should be provided to the borrowers and they should receive reasonable amount of loan which should be useful to their business. Furthermore, elder people and people with better business experience are able to repay their loan amount timely to microfinance institutions.

Berg and Schrader (2009) researched on how micro credits can help coping up in Ethiopia and his study suggested that the results depend on the previous service and relationship of the organization with clients. He evaluated microcredit system in terms of their service during economic shock which helped us to get a more detailed picture of the effect of quasi-formal credits. Cheolsung Park (2006) compared the behavior of rural people in Bangladesh during the shock when they are exposed to the insurance networks and when they are not exposed to any insurance network. He found out that rural people are able to smooth out consumption on their own by taking self-insuring measures or by pooling risks with neighbors or extended families (Park 450). In this paper, variables like access to formal credits, access to informal credits and access to quasi-formal credits have been considered as access to any form of credit to establish a relationship with the coping mechanisms while having access to any credit.

There has been extensive research on the economic shocks, coping strategies and factors that affect the coping mechanisms but very few discussed the long-term effect of the coping mechanisms. Also, there is not much research on the recent microfinance organizations that have been helping households to have more access to credits but this is evidently influencing the coping mechanism and the long-term effect of them as well. Thus this paper tries to address the gaps in these literatures. The recent dataset has enabled us to look into more details of the model. Following questions are addressed in this paper with the help of household level data of the nationally representative survey conducted in 2009 and 2010:

- What kind of shocks did the households face in 2009 and 2010 and do they cope by eroding savings/ assets/ capitals?

- Who are more vulnerable and tend to take erosive measures for coping? 
Access to Credits and Erosive or Non-erosive Coping Strategies: An Empirical Analysis in ...

- Does access to any kind of credits help households to take rather non-erosive than erosive measures for coping?

- Does this vary by the different regions the same way shocks vary by different locations?

\section{Research Methodology}

\subsection{Data Sources and Data Description}

The data used for this study are taken from the Institute of Microfinance $(\operatorname{In} M)$ for the years 2009 and 2010. Bangladesh is an agro based country where most people live in rural areas. The country has been going through an impressive record for growth and development in education, health and poverty reduction. But it's also a country which is vulnerable to natural disasters. The paper utilized a detailed survey that collected the information of household to analyze coping mechanisms. A total number of 8,936 households were selected from six major divisions (regions) of Bangladesh among which 6,636 households are rural.

As the time period covered by the dataset is 2009 and 2010, it doesn't provide much information about the dynamics of coping strategies but the coverage of different regions helps to give us a comprehensive idea of the effects faced by the people from the distribution of shocks in different areas over the years.

\subsection{Descriptive Analysis of Shocks and Coping Mechanism}

Bangladesh is a small developing country and people here suffer from income shocks around the year. Natural disasters, death or injury of the family member, the death of livestock, business loss, hypocrisy, theft or robbery, irregularity in remittance income are the income shocks that these households in the data faced. Figure 1 shows the percentage of people affected by different income shocks.

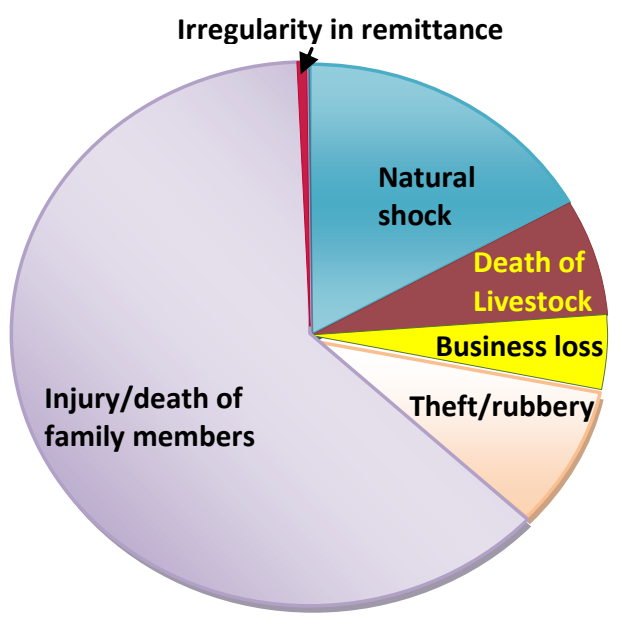

Figure 1. Types of Shocks in Bangladesh (2009-2010) 
Figure 1 shows that the most of the people suffer from income shock due to injury or death of a family member which is representative of the whole country. The high expense of medical treatments, limited income, and dependency on one particular member of the household are the primary reasons for majority of the population to be affected due to the health problem of a family member. And the next way people are most affected is by natural shock which shows that Bangladesh is a disaster prone country. As this paper wants to analyze the study for different regions in Bangladesh as well, the dataset helps us to see the scenario of six regions in terms of how much people are being affected due to the natural shocks. An idea of statistics can be given for different divisions according to the data. The Table 1 below shows the percentage of population affected due to natural shock in six divisions in Bangladesh.

\section{Table 1. Percentage (\%) Affected by Natural Shock}

\begin{tabular}{lccc}
\hline \multirow{2}{*}{ Divisions } & \multicolumn{3}{c}{ Affected by Natural Shocks? } \\
\cline { 2 - 4 } & $391(8.61 \%)$ & Yes & Total \\
\hline Barisal & $605(13.33 \%)$ & $75(1.65 \%)$ & $466(1.26 \%)$ \\
\hline Chittagong & $1,155(25.44 \%)$ & $17(0.9 \%)$ & $646(10.26 \%)$ \\
\hline Dhaka & $182(4.01 \%)$ & $183(4.03 \%)$ & $1,329(29.27 \%)$ \\
\hline Khulna & $1,299(28.61 \%)$ & $239(5.26 \%)$ & $1,538(8.04 \%)$ \\
\hline Rajshahi & $186(4.1 \%)$ & $10(0.22 \%)$ & $196(4.32 \%)$ \\
\hline Sylhet & $3.818(84.1 \%)$ & $722(15.9 \%)$ & $4,540(100.00 \%)$ \\
\hline Total &
\end{tabular}

Source: Authors' calculation

The data shows that population of Rajshahi and Khulna divisions get affected more than others. The northern part of Bangladesh is more vulnerable because of 'Monga'. The term 'Monga' is used to indicate the occurrence of acute deprivation and starvation due to an erosion of purchasing power from the lack of gainful employment opportunities and it represents 10 percent of the country's total population and occupies 11 percent land of Bangladesh (Paul et al., 2013).

Households try to smooth out consumption after they get affected by natural disasters. The coping mechanism taken after being affected by the shock can be defined into two categories, erosive and non-erosive. Poor people usually take measures eroding their assets/ lands/ labor/ savings etc. Table 2 is the statistical table showing the various coping strategies that have been taken by the population of our data. This table shows that majority of the people use up their savings to cope and smooth out the consumption which may bring a long-term negative effect on the sustainability. Those who have access to credits usually use the credits for coping. Nowadays some NGOs, and microfinance organizations are working and initiating many effective programs for the affected population in Bangladesh. The government is also increasing the budget every year for safety net programs. Another table is presented below to show the percentage of people having access to different type of credits. 
Access to Credits and Erosive or Non-erosive Coping Strategies: An Empirical Analysis in ...

Table 2. Types and Percentage (\%) of Coping Strategies Adopted

\begin{tabular}{lcc}
\hline \multicolumn{1}{c}{ Coping Strategies } & Percentage (\%) of households coped & Frequency \\
\hline Using savings & 31.94 & 1450 \\
Using insurance & 0.26 & 12 \\
Using relative support & 15.66 & 711 \\
Using government support & 0.48 & 22 \\
Using private support & 0.93 & 42 \\
Using credit & 14.60 & 663 \\
Using advance labor sale & 3.44 & 156 \\
Using advance crop sale & 3.11 & 141 \\
Using distress asset sale & 3.74 & 170 \\
\hline Source: Authors' calculation & &
\end{tabular}

From the Table 3 it can be observed that $54.81 \%$ of people have access to any forms of credit and $45.19 \%$ doesn't have any access to credits. Quasi-formal credits are playing a good role in terms of assisting rural people with coping and the data is also showing that most people who have any access to credits have access to quasiformal credits.

Table 3. Types and Percentage (\%) of Credits Taken

\begin{tabular}{lccc}
\hline Access to any Credits & Frequency & $\begin{array}{c}\text { Relative } \\
\text { Frequency (\%) }\end{array}$ & $\begin{array}{c}\text { Cumulative } \\
\text { Relative } \\
\text { Frequency (\%) }\end{array}$ \\
\hline Access to formal Credit & 403 & 4.51 & 4.51 \\
Access to informal credit & 1,007 & 11.27 & 15.78 \\
Access to quasi-formal credit & 2,430 & 27.19 & 42.97 \\
Access to formal \& informal credit & 116 & 1.30 & 44.27 \\
Access to formal \& quasi-formal credit & 107 & 1.20 & 45.47 \\
Access to informal \& quasi-formal credit & 774 & 8.66 & 54.13 \\
Access to all forms of credit & 61 & 0.68 & 54.81 \\
No access to credit & 4,038 & 45.19 & 100 \\
Total & $\mathbf{8 , 9 3 6}$ & $\mathbf{1 0 0}$ & \\
\hline
\end{tabular}

Source: Authors' calculation

This paper will use an econometric model to analyze the coping mechanism and long-term effects of the coping strategies with the access to any form of credits.

\subsection{Hypothesis and the Estimation Method}

As we have discussed above, it was mentioned previously that poorer households tend to take erosive measures and are more vulnerable in setting themselves out on the poverty cycle than the others. But this paper would like to address what might help them to cope better. And in order to analyze that it is important to test whether having access to credits help them cope better or not, help them take non-erosive measures when they face any shock.

The expected result is to get a negative relation between erosive coping strategies 
and having access to credits where the relationship will be analyzed by the following methodology,

Erosive or not $=$ Affected by any shock, have any access to credits $+b^{*}$ (Affected by any shock, have any access to credits) + Control Variables

Whether the household is taking erosive measures or not is being defined by the variables, in the following ways: whether a household is using up their savings or not, whether a household is taking the help of private supports, taking the help of relatives, whether the household is doing advance crop sale, advance labor sale and distress asset sale. The data has numerous shocks such as, affected by natural shock, affected by livestock death, affected due to business loss or fish cultivation, affected due to injury or death of family member, affected by hypocrisy or theft or robbery, affected by irregularity in remittance income. If a household faced any of this mentioned shock they are defined as yes in any shock and no otherwise. And if a household has access to formal, informal or quasi-formal credits they are defined as yes in any access to credits and no otherwise. A new variable has also been created in order to find out the relationship which is if a household is affected by any shock and if that household has access to any credit. According to the data, $74.53 \%$ of people take erosive measures and $31.62 \%$ of people that are affected by shock have access to credits.

As our dependent variable takes two values only, 'Yes and No', so, we need to test the likelihood ratio and in order to do that we need to run the logistic regression,

$\operatorname{Logit}\left(\mathrm{P}_{\text {erosive }}\right)=\log \left(\frac{\mathrm{P}_{\text {erosive }}}{1-\mathrm{P}_{\text {erosive }}}\right)=\beta_{0}+\beta_{1} \mathrm{x}_{1}+\beta_{2} \mathrm{x}_{2}+\cdots+\beta_{\mathrm{j}} \mathrm{x}_{\mathrm{j}}$

Where,

$P_{\text {erosive }}$ is the probability that an individual household is taking erosive measures;

$\beta_{0}$ is the probability constant;

$\beta_{1}$ is the co-efficient of the independent variables (if the household is affected by any shock and have any access to credits) that we are looking for to test the hypothesis.

We see that this logistic model is also providing the odds of dependent variable which is the ratio of the probability of having erosive measures vs. not having it. We will follow the same model to test the hypothesis for each division as well. To indicate the marginal effects we translate the equation into following,

$$
\begin{aligned}
& \frac{P_{\text {erosive }}}{1-P_{\text {erosive }}}=\mathrm{e}^{\mathrm{x}_{\mathrm{i}}\left(\beta_{0}+\beta_{1}+\beta_{2}+\beta_{3}+\ldots .\right)} \\
& \mathrm{P}_{\text {erosive }}=\left(1-\mathrm{P}_{\text {erosive }}\right) \mathrm{e}^{\beta_{0}+\mathrm{x}_{\mathrm{i}}\left(\beta_{1}+\beta_{2}+\beta_{3} \ldots . . .\right.} \\
& \left.\mathrm{P}_{\text {erosive }}=\mathrm{e}^{\beta_{0}+\mathrm{x}_{\mathrm{i}}\left(\beta_{1}+\beta_{2}+\beta_{3} \ldots . .\right)}-\mathrm{P}_{\text {erosive }} * \mathrm{e}^{\beta_{0}+\mathrm{x}_{\mathrm{i}}\left(\beta_{1}+\beta_{2}+\beta_{3} \ldots . .\right.}\right) \\
& \left.\mathrm{P}_{\text {erosive }}+\mathrm{P}_{\text {erosive }} * \mathrm{e}^{\beta_{0}+\mathrm{x}_{\mathrm{i}}\left(\beta_{1}+\beta_{2}+\beta_{3} \ldots . .\right.}\right)=\mathrm{e}^{\beta_{0}+\mathrm{x}_{\mathrm{i}}\left(\beta_{1}+\beta_{2}+\beta_{3} \ldots . .\right)} \\
& \left.\left.\mathrm{P}_{\text {erosive }}\left(1+\mathrm{e}^{\beta_{0}+\mathrm{x}_{\mathrm{i}}\left(\beta_{1}+\beta_{2}+\beta_{3} \ldots . . .\right.}\right)\right)=\mathrm{e}^{\beta_{0}+\mathrm{x}_{\mathrm{i}}\left(\beta_{1}+\beta_{2}+\beta_{3} \ldots . . .\right.}\right)
\end{aligned}
$$


Access to Credits and Erosive or Non-erosive Coping Strategies: An Empirical Analysis in ...

$$
\begin{aligned}
& P_{\text {erosive }}=\frac{\left.e^{\beta_{0}+x_{i}\left(\beta_{1}+\beta_{2}+\beta_{3} \ldots . . .\right.}\right)}{\left(1+e^{\beta_{0}+x_{i}\left(\beta_{1}+\beta_{2}+\beta_{3} \ldots . . .\right.}\right)} \\
& \frac{d P_{\text {erosive }}}{d x}=\frac{d}{d x}\left(\frac{e^{\beta_{0}+x_{i}\left(\beta_{1}+\beta_{2}+\beta_{3} \ldots . .\right)}}{\left(1+e^{\beta_{0}+x_{i}\left(\beta_{1}+\beta_{2}+\beta_{3} \ldots . . .\right)}\right)}\right) \\
& \frac{d P_{\text {erosive }}}{d x}=\frac{\beta_{i} e^{\beta_{0}+x_{i} \beta_{i}}}{1+e^{\beta_{1}+x_{i} \beta_{i}}}-\frac{\left(e^{\beta_{0}+x_{i} \beta_{i}}\right)^{2} \beta_{i}}{\left(1+e^{\beta_{0}+x_{i} \beta_{i}}\right)^{2}} \\
& \frac{d P_{\text {erosive }}}{d x}=\beta_{i}\left(\frac{e^{\beta_{0}+x_{i} \beta_{i}}}{\left(1+e^{\beta_{0}+x_{i} \beta_{i}}\right)^{2}}\right)
\end{aligned}
$$

Here, $\beta_{\mathrm{i}}$ is representing the value for likelihood of taking erosive measures for a unit change in access to credits if the household gets affected by economic shock. According to the hypothesis, the result should be negative which means for positive changes in access to credit there should be a negative effect in erosive measures.

\section{Empirical Results}

The logistic regression of the model (Table A1) shows the relation between taking erosive measures and when having access to credits and affected by any shocks. According to the result, the value of $\beta_{1}$ is -1.974 which refers to the fact that if a household is affected by any shock and if that household has access to any credits then the household is less likely to take erosive measures. Now if we look the marginal effects it says that having access to any credits for a household that has been affected by any shock is the household being $31.11 \%$ less likely to take any erosive measure. The ratio of having erosive coping vs. non-erosive coping for a household that has been affected by any shock and has access to any credits is less likely [as the result is $0.113(<1)$ ]. Also, the result shows that $75.98 \%$ of the values in the model is correctly specified which means that the model is a moderate indicator of the regression results.

Using different control variables the regression has been run and the result is always negative for having access to credits and taking erosive coping measures. These results prove that people are less likely to have taken coping measures that erode their savings/ lands/ assets/ labors etc., if they have access to any kind of credits. The method of maximum likelihood that is to say logistic regression has been used to reach the outcomes. A regression in Table A1 has been added to show to observe the relation (in Appendix). Also, logistic regressions for six regions (divisions) have been run in order to analyze the model for different regions and to indicate the relationship. The results are tabled in the appendix section of table $A 2$, $A 3, A 5, A 6, A 7$, and $A 8$, respectively.

From these tables, it can be seen that for all the divisions the relation is negative which again is showing that the population that has access to any credit system are 
less likely to take erosive coping measures during economic shocks. After analyzing the results we can say that the households of Barisal and Rajshahi are in worse condition than others. The less the number is the more people tend to take erosive coping. Even though they are 1.5 and 1.7 less likely to take erosive measures for coping if they have access to credits, the number is still less than other divisions stating that the population from those areas are more likely to take measures that would cause long-term negative effects later on. If we carefully looked into the research we could bridge the information given before that northern part of Bangladesh is more vulnerable for 'Monga'. The population is poorer in the northern part of Bangladesh. So they are more likely to suffer in the long run as well if they face any economic shock. This result highlights the possible sharpening of regional income inequality in Bangladesh.

\section{Policy Recommendation and Conclusion}

Some coping measures have long-term negative effect because it includes eroding assets, lands, savings etc. and income inequality is one of the main reasons for it to be more prevalent.

Adoption of erosive coping mechanisms in the event of facing economic shocks has long-term implications in terms of depletion of productive assets, investment in human capital of the future generations, leading to an entrapment in the intergenerational poverty trap. A household resorting to erosive coping may not be able to replenish productive assets and face lower productivity, lower income and as a consequence, possibly falling into a poverty trap. Moreover, lower income would lead to lower or lower-quality investment in health and education of the future generations, leading to a lower level equilibrium of low productivity, and low income. This would have serious consequences for the income inequality, and overall poverty scenarios, and growth and development of the country. This paper contributes in showing the regional disparity in coping. Uneven regional development and growth hinders the country's overall performance in the short and long run.

The developing countries often are rigged with corruption and misappropriation of public funds. The infrastructure development funds allocated for natural calamities, Government program funds for the provision of school lunch and study materials, scholarships, health clinics, and safety net programs, need to be monitored carefully. Otherwise, the vulnerable group may fall into an intergenerational lower level poverty trap of low productivity, low income, and low human capital.

We have highlighted the importance of insurance in the context of coping from different shocks. Formal insurance is virtually non-existent in rural Bangladesh. Only one percent of the population in the entire country has formal insurance of any kind. Micro-insurance is becoming popular but still the coverage is quite low. This has significant promise of helping rural agricultural households to cope better 
and not deplete the financial capital or physical assets. Government and NGO partnership is warranted in this respect.

Regional imbalance in access to credit, insurance and social safety net is another area where special attention needs to be given. People in remote, rural areas are most vulnerable to fall into the poverty trap. Access to credits and other support systems both from the Government and Non-Government sources should be increased in remote but natural calamity prone coastal and drought-prone northern parts of the country.

This paper finds that adoption of erosive strategies is relatively higher for extremely poor households. This again signifies the importance of proper targeting of a vulnerable population for safety net programs. The micro-finance organizations can provide flexible, low-interest credit to these vulnerable client groups.

Policies pursuing income equality must have important economic benefits in terms of avoiding damage costs in a natural disaster-prone country like Bangladesh. The government is increasing the budget for safety net programs every year which is a good sign for Bangladesh economy. But majority of people are not even aware of the fact that government is providing these programs. This information gap, later on, causes the deprivation of rural population from getting the help of government because most of the time the government workers take advantage of the information gap. So, the government should ensure that the help is reaching out to households properly. The household should be aware of all the possible ex-post coping availabilities so that they can take the best decision according to their condition.

Several pieces of research have shown that microfinance or quasi-formal credits are playing quite a good role in mitigating the damages of economic shocks. All the microfinance organizations should make sure that the households are aware of their programs and in no way they get deprived of any of their assistance. Overall the people should have more exposure to credits and all the information regarding them. The increase in the availability of medical facilities, life insurance, and education insurance is the policy that should be implemented in order to prevent households from taking erosive measures that have a negative effect in the long run.

We can summarize our findings as follows. First, being a disaster-prone and developing country various shocks affect a large share of households in Bangladesh. Our survey of total 8,936 households of 2009 and 2010, almost 4,535 of the households have faced shocks which are more than $50 \%$. As the shocks are almost inevitable for some regions in Bangladesh, it is noticeable that poorer households are more likely to use coping mechanisms that could have negative implications in the long run as they include the depletion of capitals, assets, savings etc. The econometric analysis demonstrates that more access to credit is 
associated with less possibility of undertaking erosive coping measures. A wide network of microfinance institutions could provide a potential platform to improve the coping mechanism which will have fewer effects in the long-term. Also as there is a large portion of people living in extreme poverty, there should also be more public safety net programs to respond to various economic shocks.

\section{References}

Berg, G. \& Schrader, J. (2009). Can Microcredit Help to Cope with Aggregate Shocks? Evidence from Ecuador, Working Paper Presented at the First European Microfinance Conference at the Free University of Brussels, Brussels, Belgium

Brouwer, R., Akter, S., Brander, L. \& Haque, E. (2007). Socioeconomic Vulnerability and Adaptation to Environmental Risk: A Case study of Climate Change and Flooding in Bangladesh. Risk Analysis, 27(2), 313-325. https://doi.org/10.1111/j.15396924.2007.00884.x

Diagne, A., \& Zeller, M. (2001). Access to credit and its impact on welfare in Malawi (Vol. 116). Intl Food Policy Res Inst. https://doi.org/10.2499/0896291197rr116

Hodgson, R. (1995). Housing Improvements: Disaster Response or Hazard Mitigation? Examples from Bangladesh. Hazards in the Built Environment, 21(2/3), 154-163.

Institute of Microfinance. (2011).Risks. Retrieved from http: www.inm.org.bd

Kuchler, A., Longborg, J., \& Nielsen, O. (2012). Shocks and Risk Coping Strategies among Poor Rural Households in Mozambique. University of Southern Denmark Working paper. Retrieved from http://static.sdu.dk/mediafiles/6/5/4/\%7B6544DE32-9A27-4D2F-9FCBD8B14F9CA23E\%7DJonas.pdf

Park, C. (2006). Risk Pooling between Households and Risk-coping Measures in Developing Countries: Evidence from Rural Bangladesh. Economic Development and Cultural Change, 54(2), 423-457. https://doi.org/10.1086/497013

Pasha, S. A. M., \& Negese. T., (2014). Performance of Loan Repayment Determinants in Ethiopian Micro Finance - An Analysis. Eurasian Journal of Business and Economics, 7 (13), 29-49.

Paul, S. K., Hossain, M. N., \& Ray, S. K. (2015). 'Monga' in northern region of Bangladesh: a study on people's survival strategies and coping capacities. Rajshahi University Journal of Life \& Earth and Agricultural Sciences, 41(41). https://doi.org/10.3329/rujleas.v41i0.21620

Opondo, D. O. (2013). Erosive coping after the 2011 floods in Kenya. International Journal of Global Warming, 5(4), 452. https://doi.org/10.1504/IJGW.2013.057285

Santos, I., Sharif, I., Rahman, H. Z., \& Zaman, H. (2011). How Do the Poor Cope with Shocks in Bangladesh? Evidence from Survey Data. Policy Research Working Papers. doi:10.1596/18139450-5810. https://doi.org/10.1596/1813-9450-5810

Varangis, P., Skees, J., \& Siegel, P. (2002). Can Financial Markets be Tapped to Help Poor People Cope with Weather Risks? Policy Research Working Papers. doi:10.1596/1813-94502812. https://doi.org/10.1596/1813-9450-2812

Yamauchi, F., Yohannes, Y., \& Quisumbing, A. (2009). Risks, Ex-Ante Actions And Public Assistance: Impacts Of Natural Disasters On Child Schooling In Bangladesh, Ethiopia And Malawi. Policy Research Working Papers. https://doi.org/10.1596/1813-9450-4909 


\section{Appendices}

\section{Table A1. Logistic regression solutions for likelihood of taking Erosive measures when having Access to Credits and affected by any Shocks}

\begin{tabular}{lcc}
\hline $\begin{array}{l}\text { Method: Maximum Likelihood } \\
\text { Dependent Variable: Erosive Coping Measures }\end{array}$ & \multicolumn{1}{l}{ Model 1 } & Model 2 \\
\hline Variables & 6,604 & 3,406 \\
\hline Observations & $1.959^{* * *}(0.140)$ & $2.360^{* * *}(0.220)$ \\
\hline Constant & $-1.974^{* * *}(0.0630)$ & $-1.798^{* * *}(0.0844)$ \\
Affected by any shocks and having access to credits & $0.000812(0.00268)$ & \\
Age of family head & $0.0216^{* * *}(0.00784)$ & \\
Years of schooling of family head & $0.0756^{*}(0.0449)$ & \\
Number of male members in family & $0.0181(0.0421)$ & \\
Number of female members in family & $-0.130^{* *}(0.0509)$ & \\
Number of educated male & $-0.0554(0.0514)$ & \\
Number of educated female & & $-0.0925(0.0914)$ \\
Is the head educated? & & $-0.421^{* *}(0.168)$ \\
Sex of the head of family & & $-0.00035(0.00032)$ \\
Own agriculture land & & $1.99 \mathrm{e}-08(2.21 \mathrm{e}-08)$ \\
Own land asset value & & $-0.235^{* *}(0.109)$ \\
Is the household poor? & & $0.243^{*}(0.140)$ \\
Is he household extremely poor? & & \\
Note: $* * *, * *, *$ indicate significance at $1 \%, 5 \%$, and $10 \%$ respectively. The Standard errors are shown in \\
parentheses. Source: Output from Stata/SE 12.0 based on Institute of Microfinance data $(2009-2010)$
\end{tabular}

\section{Table A2. Logistic regression solutions for likelihood of taking Erosive measures when having Access to Credits and affected by any Shocks in Barishal Division}

\begin{tabular}{lcc}
\hline Method: Maximum Likelihood & & \\
Dependent Variable: Erosive Coping Measures & Model 1 & Model 2 \\
\hline Variables & 457 & 224 \\
Observations & $1.295^{* *}(0.521)$ & $3.155^{* * *}(0.909)$ \\
Constant & $-1.552^{* * *}(0.217)$ & $-1.960^{* * *}(0.340)$ \\
Affected by any shocks \&having access to credits & $-0.0120(0.00831)$ & \\
Age of family head & $-0.0263(0.0269)$ & \\
Years of schooling of family head & $0.0483(0.155)$ & \\
Number of male members in family & $0.0612(0.134)$ & \\
Number of female members in family & $0.160(0.172)$ & \\
Number of educated male & $0.0114(0.169)$ & $-1.078^{* * *}(0.399)$ \\
Number of educated female & & $0.555(0.705)$ \\
Is the head educated? & & $-0.00084(0.00094)$ \\
Sex of the head of family & & $-9.34 \mathrm{e}-07^{* * *}(2.99 \mathrm{e}-07)$ \\
Own agriculture land & & $-0.864^{* *}(0.405)$ \\
Own land asset value & & $-0.287(0.500)$ \\
Is the household poor? & & \\
Is he household extremely poor? & & \\
\hline Note: $* * *, * *, *$ indicate significance at $1 \%, 5 \%$, and $10 \%$ respectively. The Standard errors are shown in \\
parentheses. Source: Output from Stata/SE 12.0 based on Institute of Microfinance data $(2009-2010)$
\end{tabular}




\section{Table A3. Logistic regression solutions for likelihood of taking Erosive measures when having Access to Credits and affected by any Shocks in Chittagong Division}

Method: Maximum Likelihood

Dependent Variable: Erosive Coping Measures

\begin{tabular}{lcc}
\hline Variables & Model 1 & Model 2 \\
\hline Observations & 1,205 & 496 \\
\hline Constant & $1.827^{* * *}(0.334)$ & $3.570^{* * *(0.607)}$ \\
Affected by any shocks \& having access to credits & $-2.335^{* * *}(0.162)$ & $-2.455^{* * *}(0.270)$ \\
Age of family head & $0.00841(0.00613)$ & \\
Years of schooling of family head & $0.0348^{*}(0.0195)$ & \\
Number of male members in family & $-0.0202(0.106)$ & \\
Number of female members in family & $-0.109(0.0988)$ & \\
Number of educated male & $-0.170(0.115)$ & \\
Number of educated female & $0.118(0.119)$ & $-0.556^{* *}(0.262)$ \\
Is the head educated? & & $-1.147 * *(0.462)$ \\
Sex of the head of family & & $0.000501(0.00116)$ \\
Own agriculture land & & $-3.52 \mathrm{e}-08(3.13 \mathrm{e}-08)$ \\
Own land asset value & & $-0.489(0.320)$ \\
Is the household poor? & & $0.989 * *(0.408)$ \\
Is he household extremely poor? & & \\
\hline Note: & & \\
\hline
\end{tabular}

Note: $* * *, * *, *$ indicate significance at $1 \%, 5 \%$, and $10 \%$, respectively. The Standard errors are shown in parentheses. Source: Output from Stata/SE 12.0 based on Institute of Microfinance data (2009-2010)

\section{Table A4. Logistic regression solutions for likelihood of taking Erosive measures when having Access to Credits and affected by any Shocks in Dhaka Division}

\begin{tabular}{lcc}
\hline Variables & Model 1 & Model 2 \\
\hline Observations & 2,205 & 1,090 \\
\hline Constant & $1.594^{* * *(0.264)}$ & $2.471^{* * *}(0.387)$ \\
Affected by any shocks \& having access to credits & $-2.013^{* * *}(0.117)$ & $-1.874^{* * *}(0.156)$ \\
Age of family head & $0.00556(0.00525)$ & \\
Years of schooling of family head & $0.0403^{* * *}(0.0140)$ & \\
Number of male members in family & $0.152^{*}(0.0825)$ & \\
Number of female members in family & $0.0940(0.0824)$ & \\
Number of educated male & $-0.193^{* *}(0.0965)$ & \\
Number of educated female & $-0.0934(0.0986)$ & $-0.110(0.162)$ \\
Is the head educated? & & $-0.434(0.300)$ \\
Sex of the head of family & & $0.000313(0.000710)$ \\
Own agriculture land & & $-2.74 \mathrm{e}-08(4.34 \mathrm{e}-08)$ \\
Own land asset value & & $-0.0658(0.207)$ \\
Is the household poor? & & $0.0437(0.262)$ \\
Is he household extremely poor? & & \\
\hline
\end{tabular}

Note: $* * *, * * *$ indicate significance at $1 \%, 5 \%$, and $10 \%$ respectively. The Standard errors are shown in parentheses. Source: Output from Stata/SE 12.0 based on Institute of Microfinance data (2009-2010) 
Access to Credits and Erosive or Non-erosive Coping Strategies: An Empirical Analysis in ...

Table A5. Logistic regression solutions for likelihood of taking Erosive measures when having Access to Credits and affected by any Shocks in Khulna Division

\begin{tabular}{lcc}
\hline Variables & Model 1 & Model 2 \\
\hline Observations & 734 & 401 \\
\hline Constant & $2.359^{* * *}(0.508)$ & $0.631(0.791)$ \\
Affected by any shocks \& having access to credits & $-2.007^{* * *}(0.236)$ & $-1.800^{* * *}(0.284)$ \\
Age of family head & $-0.00314(0.0103)$ & \\
Years of schooling of family head & $0.0249(0.0296)$ & \\
Number of male members in family & $-0.0676(0.172)$ & \\
Number of female members in family & $0.0441(0.162)$ & \\
Number of educated male & $0.173(0.203)$ & \\
Number of educated female & $-0.255(0.192)$ & \\
Is the head educated? & & $0.0884(0.278)$ \\
Sex of the head of family & & $1.042^{*}(0.619)$ \\
Own agriculture land & & $-0.000448(0.00113)$ \\
Own land asset value & & $-7.99 \mathrm{e}-08(1.67 \mathrm{e}-07)$ \\
Is the household poor? & & $0.219(0.332)$ \\
Is he household extremely poor? & & $1.023^{*}(0.566)$ \\
\hline
\end{tabular}

Note: $* * *, * *, *$ indicate significance at $1 \%, 5 \%$, and $10 \%$ respectively. The Standard errors are shown in parentheses. Source: Output from Stata/SE 12.0 based on Institute of Microfinance data (2009-2010)

Table A6. Logistic regression solutions for likelihood of taking Erosive measures when having Access to Credits and affected by any Shocks in Rajshahi Division

\begin{tabular}{lcc}
\hline Variables & Model 1 & Model 2 \\
\hline Observations & 1,621 & 1,017 \\
\hline Constant & $1.705^{* * *}(0.267)$ & $2.131^{* * *}(0.411)$ \\
Affected by any shocks \& having access to credits & $-1.795^{* * *}(0.125)$ & $-1.644^{* * *}(0.151)$ \\
Age of family head & $-0.00248(0.00520)$ & \\
Years of schooling of family head & $0.0143(0.0150)$ & \\
Number of male members in family & $0.187^{* *}(0.0892)$ & \\
Number of female members in family & $0.0247(0.0817)$ & \\
Number of educated male & $-0.178^{*}(0.0992)$ & \\
Number of educated female & $-0.00300(0.100)$ & \\
Is the head educated? & & $-0.0475(0.165)$ \\
Sex of the head of family & & $-0.247(0.306)$ \\
Own agriculture land & & $3.74 \mathrm{e}-05(0.000646)$ \\
Own land asset value & & $-3.66 \mathrm{e}-08(6.15 \mathrm{e}-08)$ \\
Is the household poor? & & $-0.384^{* *}(0.190)$ \\
Is he household extremely poor? & & $0.198(0.240)$ \\
\hline
\end{tabular}

Note: $* * *, * *, *$ indicate significance at $1 \%, 5 \%$, and $10 \%$ respectively. The Standard errors are shown in parentheses. Source: Output from Stata/SE 12.0 based on Institute of Microfinance data (2009-2010) 
Meherun AHMED, Iftekhar Uddin Ahmed CHOWDHURY \& Sabiha Subah MOHONA

Table A7. Logistic regression solutions for likelihood of taking Erosive measures when having Access to Credits and affected by any Shocks in Sylhet Division

\begin{tabular}{lcc}
\hline Variables & Model 1 & Model 2 \\
\hline Observations & 382 & 178 \\
\hline Constant & $1.979^{* * *}(0.551)$ & $2.779^{* *}(1.276)$ \\
Affected by any shocks \& having access to credits & $-2.212^{* * *}(0.279)$ & $-1.364^{* * *}(0.433)$ \\
Age of family head & $-0.00732(0.00927)$ & \\
Years of schooling of family head & $0.00884(0.0340)$ & \\
Number of male members in family & $-0.0539(0.152)$ & \\
Number of female members in family & $0.306^{* *}(0.152)$ & \\
Number of educated male & $-0.00676(0.180)$ & \\
Number of educated female & $-0.402^{* *}(0.183)$ & \\
Is the head educated? & & $0.610(0.524)$ \\
Sex of the head of family & & $-2.292^{* *}(1.050)$ \\
Own agriculture land & & $-0.00325^{* *}(0.00146)$ \\
Own land asset value & & $2.86 \mathrm{e}-07^{*}(1.53 \mathrm{e}-07)$ \\
Is the household poor? & & $0.427(0.555)$ \\
Is he household extremely poor? & $-0.375(0.774)$ \\
\hline Note: $* * *, * *, *$ indicate significance at $1 \%, 5 \%$, and $10 \%$ respectively. The Standard errors are shown in \\
parentheses. Source: Output from Stata/SE 12.0 based on Institute of Microfinance data $(2009-2010)$
\end{tabular}

